\title{
Diagnosis of Severe Protein C Deficiency Confirmed by Presence of Rare PROC Gene Mutation
}

Myung Seop Lim, M.D., Jung Eun Shin, M.D., Soon Min Lee, M.D., Ho Sun Eun, M.D., Min Soo Park, M.D., Kook In Park, M.D., Ran Namgung, M.D., Kyung A Lee, M.D.* , and Jin Sung Lee, M.D. ${ }^{\dagger}$

Departments of Pediatrics, Laboratory Medicine*, and Clinical Genetics ${ }^{\dagger}$, Yonsei University College of Medicine, Seoul, Korea

\section{ABSTRACT}

Protein C (PROC) deficiency is caused by mutations in the PROC gene on chromosome 2q14.3. Patients with $P R O C$ deficiency typically present distinguished purpura, intracerebral and intravascular coagulopathy, and ophthalmologic complications. Here, we report a rare severe form of $P R O C$ deficiency resulting from a compound heterozygosity in PROC. The patient was a 5-day-old female neonate born at 39 weeks of gestation with a birth weight of 2,960 $\mathrm{g}$. She was transferred to our hospital with running a fever at $38.5^{\circ} \mathrm{C}$ and with dark red patches on her feet. At admission, a complete blood count showed no specific findings, but levels of $P R O C$ and protein $\mathrm{S}$ were abnormally low ( $1 \%$ and $68 \%$, respectively). Magnetic resonance imaging revealed intracerebral hemorrhaging and parenchymal damage with dysplasia of the brain. Ophthalmologic examination revealed vitreous hemorrhaging with retinal detachment. Genetic testing revealed a missense mutation (Arg211Trp) and a frameshift mutation (Gly239Serfs*8) in PROC, inherited from the father and mother, respectively. The patient recovered from purpura after undergoing ventriculoperitoneal shunting and treatment with fresh frozen plasma, warfarin sodium, and PROC concentrate. This is the first report of severe neonatal PROC deficiency with purpura fulminans, vitreous hemorrhage, and intracerebral hemorrhage confirmed via $P R O C$ genetic testing, which identified a rare compound heterozygosity of $P R O C$.

Key Words: Protein C deficiency, Fulminans purpura, Genetic testing, PROC gene

\section{INTRODUCTION}

Congenital protein $\mathrm{C}(P R O C)$ deficiency is a well-documented autosomal dominant disorder of variable penetrance. Over 150 mutations have been reported ${ }^{1)}$. PROC, located on chromosome 2q14.3 is approximately 10,802 bp and contains 9 exons (1,790 bp), 8 of which encode the protein ${ }^{2-4)}$.

Severe $P R O C$ deficiency ( $P R O C$ activity $<1 \mathrm{IU} / \mathrm{dL}$ ) is a rare autosomal recessive disorder; its chief presentations include neonatal purpura fulminans and severe disseminated
Received: 20 July 2016

Revised: 7 October 2016

Accepted: 7 October 2016

Correspondence to: Soon Min Lee Department of Pediatrics, Yonsei University College of Medicine, Severance Children's Hospital, 50 Yonsei-ro, Seodaemun-gu, Seoul 03722, Korea

Tel: +82-2-2019-3350

Fax: +82-2-3461-9473

E-mail: smlee@yuhs.ac

Copyright(c)

By Korean Society of Neonatology.

All right reserved.

This is an Open-Access article distributed under the terms of the Creative Commons Attribution Non-Commercial License (http://creativecommons.org/licenses/ by-nc/4.0), which permits unrestricted non-commercial use, distribution, and reproduction in any medium, provided the original work is properly cited. 
intravascular coagulation (DIC) with concomitant venous thromboembolism ${ }^{5}$. The incidence of clinically significant $P R O C$ deficiency is estimated to be 1 in $20,000^{6}$. In this study, we describe the first genetically verified case of severe PROC deficiency in Korea.

\section{CASE REPORT}

The patient was a 5 -day-old female neonate, born by vaginal delivery at 39 weeks of gestation with a birth weight of 2,960 g. The patient is the first child of a mother with no remarkable medical nor obstetric history (G1, P1, A0, D0, L1). No unusual events were reported during the first 3 days after birth; however, on the 4th day, the patient was admitted to the hospital after her body temperature rose to $38.5^{\circ} \mathrm{C}$. On the 5th day, the skin on her feet turned dark red (Figure 1). When she was transferred to our hospital, she appeared acutely ill but her vital signs were within normal range (blood pressure: 78/44 mmHg, heart rate: 136 beats per minute, respiratory rate: 55 breaths per minute, body temperature: $37.5^{\circ} \mathrm{C}$ ).

Laboratory analysis revealed a white blood cell count of $20,410 / \mu \mathrm{L}$, hemoglobin of $12.6 \mathrm{~g} / \mathrm{dL}$, hematocrit of $36 \%$, and platelet count of $219,000 / \mu \mathrm{L}$. Liver and kidney function, Creactive protein levels, and the results for blood, urine, stool, and cerebrospinal fluid culture were normal. Cerebrospinal fluid analysis revealed a red blood cell count of $210,000 / \mu \mathrm{L}$, white blood cell count of $11,730 / \mu \mathrm{L}$, total protein of $2,271 \mathrm{mg} / \mathrm{dL}$, and a glucose level of $22 \mathrm{mg} / \mathrm{dL}$; the findings were suggestive of the presence of a hemorrhage. Blood coagulation tests showed a prothrombin time of $13.4 \mathrm{~s}$ (normal range: 10.0-15.3 s), activated

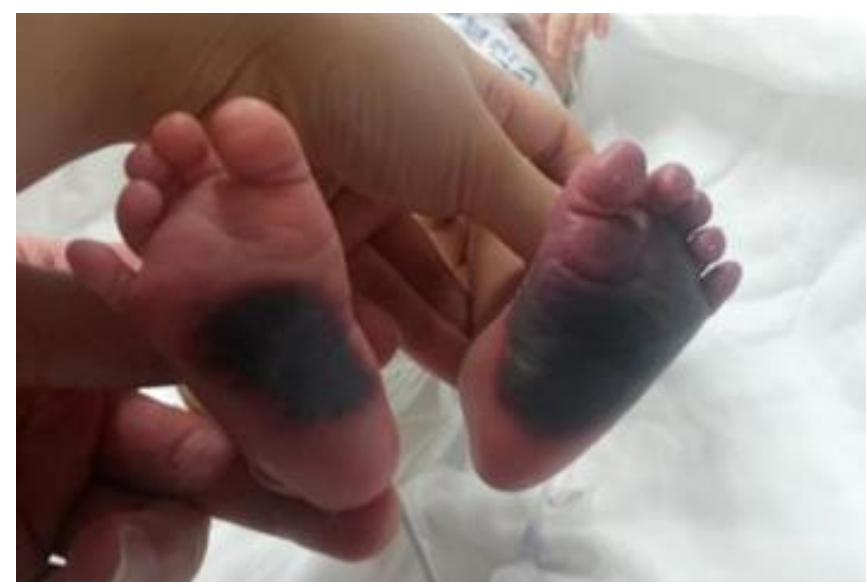

Figure 1. The purpura of feet at 5 days of age. partial thromboplastin time of $44.2 \mathrm{~s}$ (normal range: 25.4-59.8 s), fibrinogen level of $58 \mathrm{mg} / \mathrm{dL}$ (normal range: $162-462 \mathrm{mg} / \mathrm{dL}$ ), D-dimer level of $62.5 \mu \mathrm{g} / \mathrm{mL}$ (normal range: $0.0-0.5 \mu \mathrm{g} / \mathrm{mL}$ ), PROC level of $1 \%$ (normal range: 50-150\%), protein S level of $68 \%$ (normal range: $80-120 \%$ ), and antithrombin III level of $95 \%$ (normal range: $41-95 \%)$.

Neurosonography (Figure 2) and magnetic resonance imaging (MRI) of the patient's brain (Figure 3 ) at 10 days of age revealed brain parenchymal destruction, intracranial hemorrhage, and atrophic change in the right eyeball. Examination of the fundus revealed posterior synechiae.

Genetic testing revealed 2 types of mutations in PROC (Figure 4): a missense mutation (Arg211Trp) and a frameshift mutation (Gly239Serfs*8) causing deletion of residues 715-724. Arg211Trp has been associated with diseases and is often observed within the Korean population; however, Gly239Serfs*8 has not been previously reported in Koreans. Genetic testing of the parents revealed that the father was a carrier for Arg211Trp and the

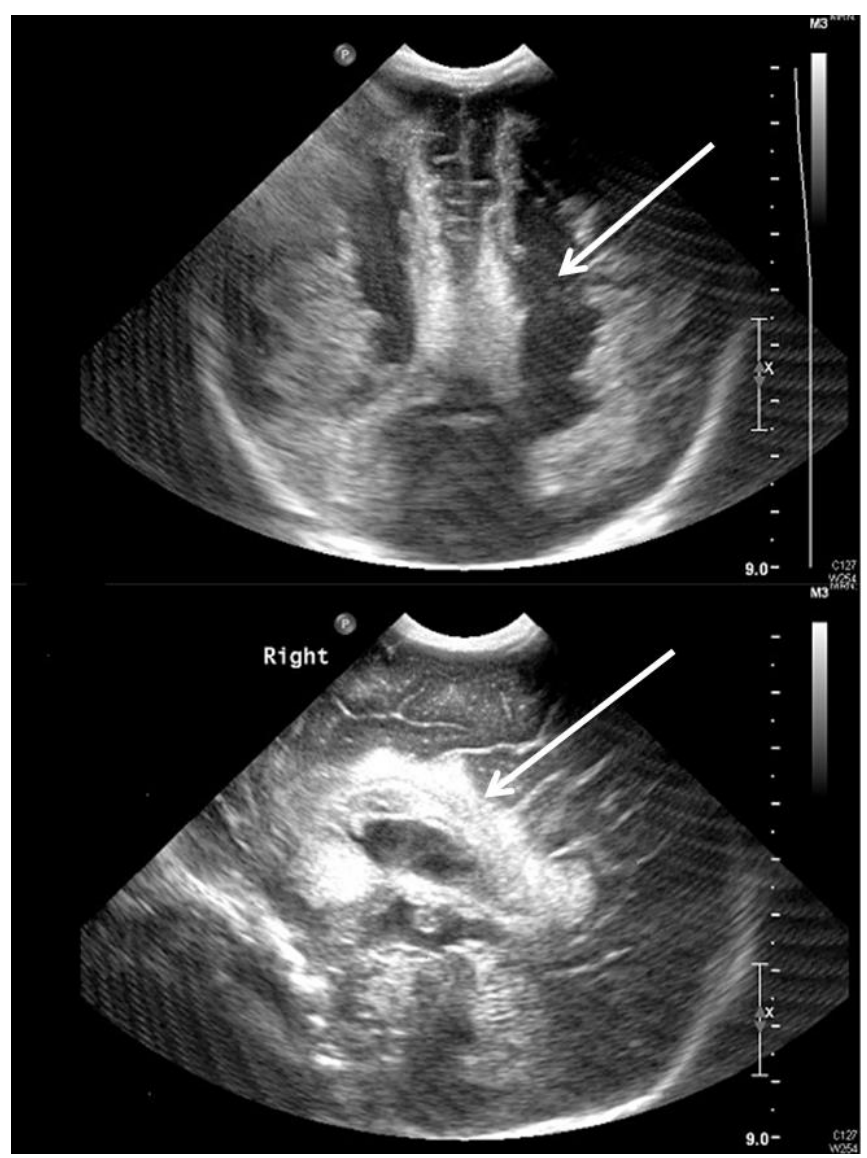

Figure 2. Neurosonogram showing symmetric hyper-echogenicity and extensive cystic parenchymal destruction communicated to ventricles (arrows). 


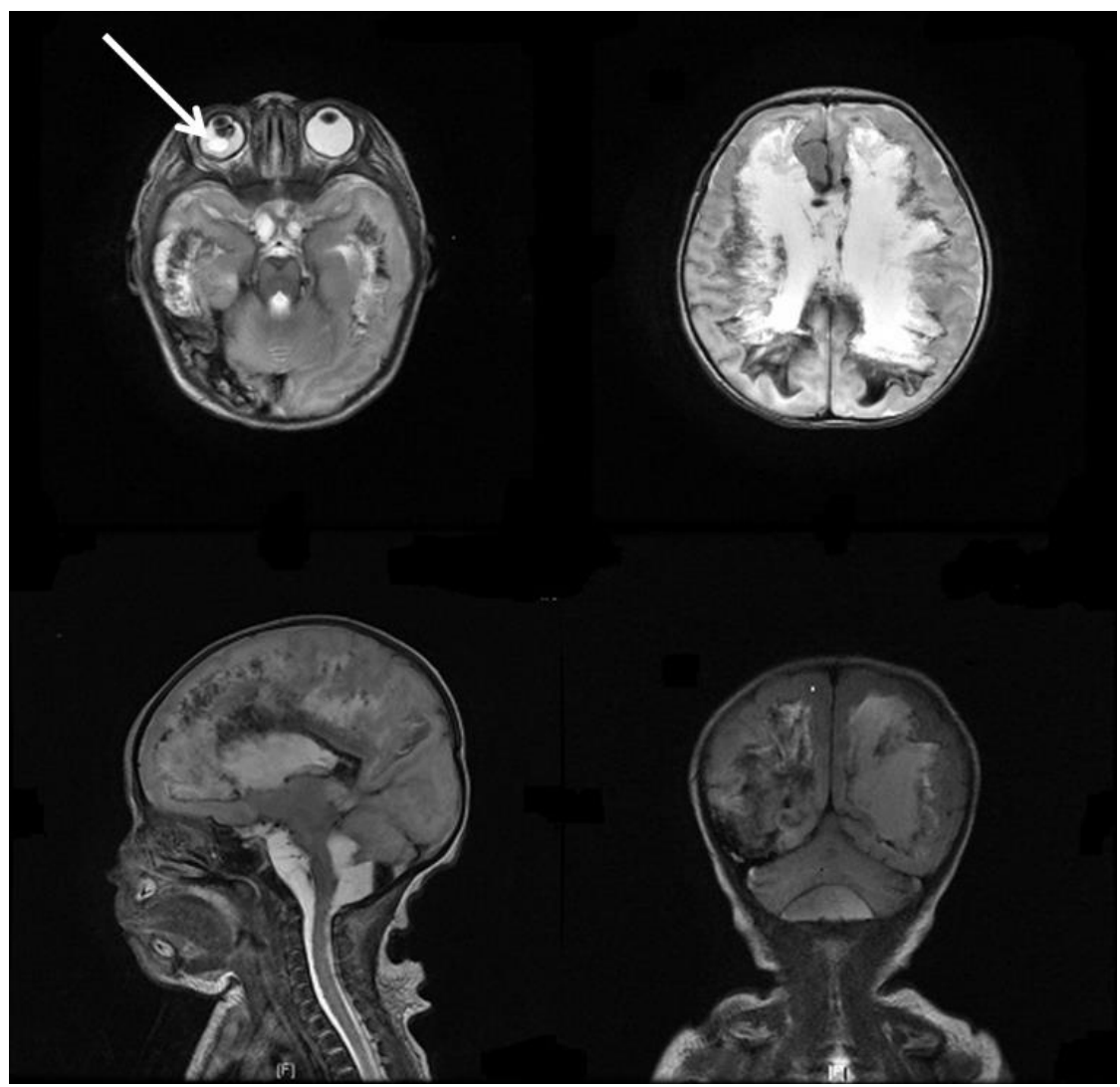

Figure 3. Brain magnetic resonance imaging (MRI) shows: subacute extensive hemorrhages in the bilateral periventricular and subcortical white matter; parenchymal destruction with leukomalatic changes; communication with lateral ventricles; atrophic change of the right eyeball (arrow), with septated fluid collection and hemorrhage in the right vitreous cavity.

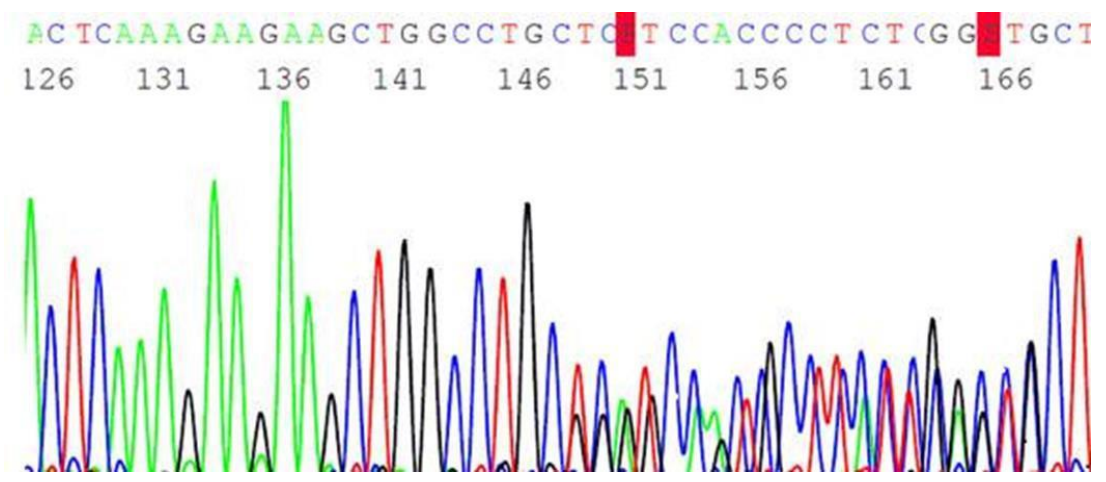

Figure 4. Genetic testing of the patient found a missense mutation (Arg211Trp) of the protein C gene, and a frameshift mutation (Gly239Serfs*8).

mother was a carrier for Gly239Serfs*8. Subsequently, the patient was confirmed to be compound heterozygous for $P R O C$, which resulted in the severe $P R O C$ deficiency.

The patient received the following treatment. Fresh frozen plasma (FFP; $10 \mathrm{mg} / \mathrm{kg}$ ) was administered twice a day for 28 days: at 5 days of age, from 10 days to 27 days of age, and from
32 days to 40 days of age. Warfarin sodium was administered at $100 \mathrm{IU} / \mathrm{kg}$ at 30 days of age, followed by administration of $50 \mathrm{IU} /$ $\mathrm{kg}$ every 12 hours for the next 5 days, and finally at $0.2 \mathrm{mg} / \mathrm{kg}$ from 34 days of age. The level of PROC increased to 37\% during the treatment period, but decreased to $10 \%$ after cessation of treatment and the patient was considered to be recovered from 
the purpura.

The patient underwent extracapsular cataract extraction via phacoemulsification and synechiolysis at 3 months of age. The post-hemorrhagic hydrocephaly was also treated by external ventricular drainage and ventriculoperitoneal shunting at 5 months of age. She was discharged at 6 months of age and her PROC levels, prothrombin time, and activated partial thromboplastin were reassessed every 6 months.

\section{DISCUSSION}

The incidence of asymptomatic and clinically significant $P R O C$ deficiency has been reported to be 1 in 200-500 and 1 in 20,000 healthy individuals, respectively ${ }^{5,7)}$. Although there have been several cases of purpura fulminans in the Korean population that were suspected to be due to $P R O C$ deficiency, none were genetically confirmed via identification of mutations in $P R O C^{8)}$.

Diagnostic testing for $P R O C$ deficiency typically relies on functional assays such as chromogenic assays containing snake venom, clotting assays, and enzyme-linked immunosorbent assays ${ }^{5}$. However, in addition to these assays, genetic testing for mutations in PROC located on chromosome 2q14.3 was also needed ${ }^{9)}$.

For a healthy term infant, the average $P R O C$ level is $40 \%$, with mild deficiency diagnosed for values up to $20 \%$, moderate-tosevere deficiency at $1-20 \%$, and severe deficiency at $<1 \%$ or if $P R O C$ is undetectable ${ }^{5,10)}$. In the present case, the patient had PROC levels of $1 \%$ upon admission.

Infants with severe congenital PROC deficiency typically present rapidly progressive purpura fulminans and DIC within hours of birth ${ }^{11)}$. Purpura fulminans begins with red or purpuric lesions caused by application of mild pressure, which eventually forms painful, palpable black eschars. Most affected infants manifest white light reflexes and are congenitally blind due to thrombosis in the developing vitreal vein. On brain MRIs, many infants show evidence of prenatal arterial ischemic stroke or cerebral hemorrhage $^{12)}$. Large vessel thrombosis, including renal vein thrombosis, has been reported in some infants ${ }^{13}$. Purpura fulminans is triggered by infection, trauma, and even minor decreases in levels of therapeutic anticoagulants ${ }^{14,15)}$. The present patient exhibited purpura fulminans, DIC, congenital blindness, and brain involvement, visual impairment and delayed development by 1 year of age.
Management of severe $P R O C$ deficiency includes an acute phase of replacement therapy with FFP or PROC concentrate, and an anticoagulant with warfarin or low-molecular-weight heparin as maintenance therapy ${ }^{16-18)}$. The treatment reported here includes administration of FFP 4-5 times per week for 1 month, $P R O C$ concentrate, and oral enoxaparin after discharge.

Twenty cases of homozygous PROC deficiency presenting neonatal purpura fulminans have been reported worldwide since 1998. Most of these cases had a poor clinical outcome, including complete blindness (75\%), severe neurological impairment (33\%), or death within the first few days after birth $(10 \%)^{19)}$. Other major morbidities, such as renal failure, epilepsy, and impaired growth and development, have also been reported. Only 3 patients have been reported to not exhibit any major morbidity because of early onset of treatment and continuous therapy with $P R O C$ concentrate ${ }^{19,20)}$.

Overall, the present study describes a case of severe $P R O C$ deficiency in a neonate that presented purpura fulminans, vitreous hemorrhage, and intracerebral hemorrhage. The diagnosis was confirmed by identification of a rare compound heterozygosity in PROC.

\section{REFERENCES}

1) Tcheng WY, Dovat S, Gurel Z, Donkin J, Wong WY. Severe congenital protein $\mathrm{C}$ deficiency: description of a new mutation and prophylactic protein $\mathrm{C}$ therapy and in vivo pharmacokinetics. J Pediatr Hematol Oncol 2008;30:166-71.

2) Cooper PC, Hill M, Maclean RM. The phenotypic and genetic assessment of protein C deficiency. Int J Lab Hematol 2012; 34:336-46.

3) Unal S, Gumruk F, Yigit S, Tuncer M, Tavil B, Cil O, et al. A novel mutation in protein $\mathrm{C}$ gene (PROC) causing severe phenotype in neonatal period. Pediatr Blood Cancer 2014; 61:763-4.

4) Al Antary ET, Haddadin IS, Hamory MK, Daauuod MM. Hypercoagulability in a newborn with concomitant homozygous factor V Leiden and severe homozygous protein C deficiency type 1. Blood Coagul Fibrinolysis 2013;24:777-9.

5) Goldenberg NA, Manco-Johnson MJ. Protein C deficiency. Haemophilia 2008;14:1214-21.

6) Dahlback B. The protein $C$ anticoagulant system: inherited defects as basis for venous thrombosis. Thromb Res 1995;77:143.

7) Jain R, T L, Chandran J, Jayandharan GR, Palle A, Moses PD. A 
novel mutation c.1048A $>$ T at codon 350 (Lys $>$ Stop) in PROC gene causing neonatal purpura fulminans. Blood Coagul Fibrinolysis 2013;24:890-2.

8) Kim YG, Na BM, Lee GC, Kim MJ, Park HJ, Kim CY, et al. Neonatal purpura fulminans due to homozygous protein $\mathrm{C}$ deficiency. Ann Dermatol 2004;16:176-9.

9) Tang L, Guo T, Yang R, Mei H, Wang H, Lu X, et al. Genetic background analysis of protein $\mathrm{C}$ deficiency demonstrates a recurrent mutation associated with venous thrombosis in Chinese population. PLoS One 2012;7:e35773.

10) Manco-Johnson MJ, Abshire TC, Jacobson LJ, Marlar RA. Severe neonatal protein $\mathrm{C}$ deficiency: prevalence and thrombotic risk. J Pediatr 1991;119:793-8.

11) Marlar RA, Montgomery RR, Broekmans AW. Diagnosis and treatment of homozygous protein C deficiency. Report of the Working Party on Homozygous Protein C Deficiency of the Subcommittee on Protein C and Protein S, International Committee on Thrombosis and Haemostasis. J Pediatr 1989; 114:528-34.

12) Kohler J, Kasper J, Witt I, von Reutern GM. Ischemic stroke due to protein C deficiency. Stroke 1990;21:1077-80.

13) Tsay W, Shen MC. R147W mutation of PROC gene is common in venous thrombotic patients in Taiwanese Chinese. Am J Hematol 2004;76:8-13.

14) Limperger V, Klostermeier UC, Kenet G, Holzhauer S, Alhenc
Gelas M, Finckh U, et al. Clinical and laboratory characteristics of children with venous thromboembolism and protein C-deficiency: an observational Israeli-German cohort study. Br J Haematol 2014;167:385-93.

15) Doring M, Rohrer KM, Tsiflikas I, Buchenau W, Wilke M, Handgretinger R, et al. A newborn with grouped facial skin lesions and subsequent seizures. BMC Pediatr 2014;14:126.

16) Chalmers E, Cooper P, Forman $K$, Grimley $C$, Khair $K$, Minford A, et al. Purpura fulminans: recognition, diagnosis and management. Arch Dis Child 2011;96:1066-71.

17) Dreyfus M, Masterson M, David M, Rivard GE, Muller FM, Kreuz W, et al. Replacement therapy with a monoclonal antibody purified protein $\mathrm{C}$ concentrate in newborns with severe congenital protein C deficiency. Semin Thromb Hemost 1995;21:371-81.

18) Hartman KR, Manco-Johnson M, Rawlings JS, Bower DJ, Marlar RA. Homozygous protein C deficiency: early treatment with warfarin. Am J Pediatr Hematol Oncol 1989;11:395-401.

19) Monagle K, Ignjatovic V, Hardikar W, Newall F, Monagle P. Long-term follow-up of homozygote protein $\mathrm{C}$ deficiency after multimodal therapy. J Pediatr Hematol Oncol 2014;36: e452-5.

20) Ohga S, Kang D, Kinjo T, Ochiai M, Doi T, Ishimura M, et al. Paediatric presentation and outcome of congenital protein $\mathrm{C}$ deficiency in Japan. Haemophilia 2013;19:37884. 